\title{
Determinants of Oral Bisphosphonate Use Beyond 5 Years
}

\author{
Monika A. Izano, PhD, MS, MA; Joan C. Lo, MD; Bruce Ettinger, MD; Susan M. Ott, MD; \\ Bonnie H. Li, MS; Fang Niu, MS; Rita L. Hui, PharmD, MS; Romain Neugebauer, PhD; \\ and Annette L. Adams, PhD, MPH
}

\begin{abstract}
BACKGROUND: Few studies have examined factors that determine bisphosphonate (BP) continuation beyond 5 years in clinical practice.

OBJECTIVE: To investigate factors associated with BP continuation among women who completed 5 years of BP therapy.
\end{abstract}

METHODS: Women who received 5 consecutive years of oral BP treatment entered the cohort during 2002-2014 and were followed up to 5 additional years. Multivariable logistic regression was used to evaluate the association of demographic and clinical factors with adherent treatment continuation.

RESULTS: The cohort included 19,091 women with a median age of 72 years. Baseline and time-varying factors associated with increased odds of BP continuation after 5 years were (a) most recent bone mineral density (BMD) T-score -2 to -2.4 (OR=1.31, 95\% $\mathrm{Cl}=1.25-1.38)$, T-score -2.5 to $-2.9(\mathrm{OR}=1.48,95 \% \mathrm{Cl}=1.39-1.57)$, and $\mathrm{T}$-score $\leq-3.0(\mathrm{OR}=1.57,95 \%$ $\mathrm{Cl}=1.47-1.68)$ versus $\mathrm{T}$-scores above -2.0 ; (b) index date before 2008 ( $0 \mathrm{R}=1.35,95 \% \mathrm{Cl}=1.29-1.41)$; and (c) diabetes mellitus $(\mathrm{OR}=1.08,95 \%$ $\mathrm{Cl}=1.01-1.16)$. In contrast, factors associated with decreased odds of BP continuation were (a) recent hip ( $0 \mathrm{R}=0.61,95 \% \mathrm{Cl}=0.52-0.71)$ or humerus $(0 \mathrm{R}=0.79,95 \% \mathrm{Cl}=0.66-0.94)$ fracture or fracture other than hip, wrist, spine, or humerus ( $\mathrm{OR}=0.90,95 \% \mathrm{Cl}=0.84-0.97)$; (b) Charlson Comorbidity Index score $>2$ ( $0 \mathrm{R}=0.91,95 \% \mathrm{Cl}=0.84-0.98)$; (c) history of rheumatoid arthritis ( $\mathrm{OR}=0.89,95 \% \mathrm{Cl}=0.80-0.99)$; (d) Hispanic ( $0 \mathrm{R}=0.89,95 \% \mathrm{Cl}=0.85-0.94)$ or Asian ( $\mathrm{R}=0.90,95 \% \mathrm{Cl}=0.85-0.94)$ race/ethnicity; and (e) use of proton pump inhibitors ( $O R=0.65,95 \%$ $\mathrm{Cl}=0.59-0.71$ ). Patient age and fracture before BP initiation were not associated with treatment continuation.

CONCLUSIONS: Clinical factors predicting continued BP treatment beyond 5 years include low BMD T-score, absence of recent fracture, and earlier era of treatment. Use of proton pump inhibitors was associated with lower likelihood of BP continuation. Other clinical and demographic factors were also noted to have variable effects on BP treatment continuation.

J Manag Care Spec Pharm. 2020;26(2):197-202

Copyright $\odot 2020$, Academy of Managed Care Pharmacy. All rights reserved.

\section{What is already known about this subject}

In patients at high risk for osteoporotic fractures, treatment with oral bisphosphonate drugs leads to substantial risk reduction within the first several years of treatment; continued treatment beyond 5 years may only benefit a subgroup of patients.

In clinical practice, factors that determine bisphosphonate continuation beyond 5 years are not well understood.

\section{What this study adds}

Key factors associated with bisphosphonate treatment continuation beyond 5 years include low bone mineral density and treatment initiation before 2008 .

Key factors associated with bisphosphonate treatment interruption after 5 years include recent fracture and use of proton pump inhibitors.

$\mathrm{N}$ itrogen-containing second-generation bisphosphonate (BP) drugs have been first-line therapies for osteoporosis, based on strong clinical trial evidence showing substantial osteoporotic fracture risk reduction in high-risk patients within the first 3-4 years of treatment. ${ }^{1,2}$ Data from a clinical trial also suggest that continuation of alendronate treatment beyond 5 years reduces the risk of symptomatic vertebral fractures but does not prevent asymptomatic vertebral fractures (those found only during radiographic examination) and, further, does not reduce the risk of other clinical fractures. ${ }^{3,4}$ However, adherence and persistence with long-term BP treatment can be problematic. Little is known about the role of clinical factors that predict continued BP use beyond 5 years in clinical practice.

In previous studies, we examined treatment adherence for the first 3 years following BP initiation and have also shown that an adherence criteria of 0.6 (based on the proportion of days covered [PDC] by the dispensed days supply of BP) provides a practical approach for characterizing continued adherence in real-world clinical settings. ${ }^{5,6}$ In the current study, we examined the association of demographic and clinical factors with BP continuation after the first 5 years of treatment. We also examined whether treatment continuation was determined by the era in which BP treatment was prescribed. This latter analysis was motivated by several considerations: (a) 2007 was the year in which published data were first disseminated suggesting that treatment continuation beyond 5 years benefits only those at high fracture risk ${ }^{7-12}$; (b) 2008 marked the year in which revised osteoporosis guidelines were published recommending assessment of calculated fracture risk when considering treatment ${ }^{13}$; and (c) the years after 2007 were notable for the first published position statements pertaining to 2 unusual late complications of treatment, osteonecrosis of the jaw and atypical femur fracture. ${ }^{14-16}$ 


\section{Methods}

\section{Study Population}

We used health plan pharmacy data within Kaiser Permanente Southern California, a large, integrated health care delivery system that provides care to more than 4 million members. Health plan pharmacy records were used to identify the study population of women who met the following inclusion criteria: (a) initiated oral BP therapy (alendronate, risedronate, or ibandronate) during 1997-2009; (b) were aged 45-84 years at the time of treatment initiation; (c) were health plan members for the 2 years previous to BP initiation; (d) received BP for 5 years and were at least $60 \%$ adherent based on the days supply of dispensed prescriptions; and (e) had no gaps in health plan membership greater than 3 months. Thus, study follow-up commenced during the years 2002-2014, after the first 5 years of treatment; we refer to this start of follow-up as the index date. Women in the study cohort were also required to have received $\mathrm{BP}$ within the 60 days before the index date.

Exclusion criteria included (a) receipt of intravenous BP, etidronate, denosumab, and teriparatide; (b) treatment with raloxifene or estrogen within 60 days before the index date; (c) evidence of advanced chronic kidney disease (grade 4 or 5 based on estimated glomerular filtration rate calculated using serum creatinine); (d) end-stage renal disease (received dialysis or renal transplant); or (e) diagnosis of secondary (metastatic) cancer beyond lymph nodes, multiple myeloma, Paget disease, osteogenesis imperfecta, hypophosphatasia, or primary hyperparathyroidism.

Our study population consisted of 19,091 women who were followed from their index dates until they either (a) discontinued BP treatment $(n=12,704)$, (b) died $(n=294)$, (c) experienced one of the aforementioned exclusion events ( $n=1313)$, (d) ended their health plan membership ( $n=589)$, or (e) reached the administrative end of follow-up (e.g., end of study September 30,2015) or reached a maximum follow-up of 5 years $(n=4,191)$.

This study was approved by the Kaiser Permanente Southern and Northern California Institutional Review Boards, and a waiver of informed consent was obtained due to the nature of the study.

\section{Exposure Assessment}

Ongoing BP exposure (including all second-generation oral bisphosphonate drugs) was determined using the days supply of dispensed drugs, where prescription/refill gaps of 1 or 2 days were bridged, and stockpiling for prescriptions that overlapped for less than 30 days was allowed. ${ }^{5}$ We considered each quarter of follow-up as being on (adherent) treatment if a woman had evidence of a PDC that was 0.6 or greater. $^{6}$

\section{Covariates}

We considered an extensive list of fixed and time-dependent fracture risk factors that might determine who remains on
BP treatment. The set of fixed covariates assessed at index date included (a) age (categorized as 50-59, 60-69, 70-79, and $\geq 80$ years); (b) self-reported race/ethnicity (categorized as white non-Hispanic, black, Hispanic, Asian/Pacific-Islander, or other/mixed/unknown); (c) indicator of being a current smoker any time within 5 years of index date; (d) estimated level of educational attainment; (e) estimated household income status; (f) history of fracture any time before BP initiation (hip, humerus, spine or wrist fracture, or fracture at other skeletal sites); (g) whether the index date was before 2008; and (h) body mass index $\left(\mathrm{BMI}, \mathrm{kg} / \mathrm{m}^{2}\right)$. In these analyses, BMI was categorized as normal/underweight $\left(<25 \mathrm{~kg} / \mathrm{m}^{2}\right)$, overweight $(25$ to $\left.<30 \mathrm{~kg} / \mathrm{m}^{2}\right)$, or obese $\left(\geq 30 \mathrm{~kg} / \mathrm{m}^{2}\right)$. Education and household income status were estimated based on the 2010 U.S. census data, with low education defined as living in a census block with more than $25 \%$ of individuals aged over 25 years having less than a 12th grade education and low income defined as living in a census block with a median household income less than $\$ 35,000$.

We classified previous fractures based on hospitalization or ambulatory diagnoses (International Classification of Diseases, Ninth Revision, Clinical Modification [ICD-9-CM] codes 805, $807-815,817-825$, and 827-829) occurring after age 40 years, excluding codes for open fractures, fractures of the head or fingers and toes, spine fractures with spinal cord injury, and hospitalized fractures associated with high energy trauma (ICD-9-CM E800-E848). ${ }^{13}$

The set of time-dependent covariates included the most recent measurements within each quarter of (a) the CharlsonDeyo Comorbidity Index score categorized as $0,1,2,3$ or more ${ }^{17}$; (b) diagnosis of diabetes mellitus with evidence of treatment; (c) rheumatoid arthritis; (d) grade 3A/3B chronic kidney disease (CKD); (e) treatment with proton pump inhibitors, aromatase inhibitors, or glucocorticoids; (f) hip, spine, humerus, wrist, or other clinical fracture within the previous 12 months; and (g) most recent bone mineral density (BMD) T-score. Models were also adjusted for length of follow-up after the index date ( $<6$ months, 6 months- 1 year, $1-2$ years, 2-3 years, 3-4 years, and 4-5 years), since duration of previous BP may affect the propensity to continue BP. In each quarter of follow-up, time-dependent covariates were assigned values in the days strictly before changes in exposure status.

Women were characterized as having diabetes if they had 2 or more separate diagnoses of diabetes mellitus and received treatment with a diabetes medication. Rheumatoid arthritis was defined based on 2 or more clinical diagnoses. Kidney function was determined based on estimated glomerular filtration rate (eGFR, $\left.\mathrm{mL} / \mathrm{min} / 1.7 \mathrm{~m}^{2}\right){ }^{18} \mathrm{~A}$ woman was classified as having grade 3B CKD if her eGFR was in the 30-44 range, and grade 3A CKD if her eGFR was in the 45-59 range. Treatment with proton pump inhibitors and aromatase inhibitors were determined from pharmacy records. Systemic glucocorticoid 
exposure was categorized using prednisone equivalents, with chronic exposure in the past year defined by a cumulative prednisone-equivalent dose $\geq 1,825 \mathrm{mg}$ over 365 days (approximating $5 \mathrm{mg}$ per day) as previously described. ${ }^{19}$

Results for BMD T-scores of the femoral neck, total hip, and lumbar spine were obtained from clinical dual-energy x-ray absorptiometry (DXA; GE Lunar) scans performed at the hip and spine, with T-scores derived using young adult female Caucasian reference data. The mean values among available measurements were used to impute missing baseline eGFR (mean: $72 \mathrm{~mL}$ / $\mathrm{min} / 1.7 \mathrm{~m}^{2}$ ) and BMD T-score measurements (mean: -1.79 for femoral neck, -1.53 for total hip, and -2.03 for lumbar spine). BMD T-score and eGFR values from the previous quarter were carried forward to the subsequent quarter of follow-up when a newer measurement was not available. In analyses, the lowest BMD T-score from any of the 3 measured sites was categorized as $>-2.0,-2.0$ to $-2.4,-2.5$ to -2.9 , and $\leq-3.0$.

\section{Statistical Analyses}

We used multivariable logistic regression with robust standard errors (generalized estimating equations) to estimate odds ratios (OR) for the association of fixed and time-dependent covariates that could predict BP continuation and could independently be associated with fracture risk.

Analytical datasets were created in SAS version 9.3 (SAS Institute, Cary, NC) using the MSMstructure, ${ }^{20}$ which was used to update BP exposure and time-dependent covariates every 90 days. All analyses were performed in R programing language, version 3.3.2 (R Foundation for Statistical Computing, Vienna, Austria). A $P$ value of $<0.05$ was considered statistically significant.

\section{Results}

Our study population included 19,091 women, whose median age was 72 years (interquartile range (IQR) $=65-78$ years); $58 \%$ of the women were white; $17 \%$ were Asian/Pacific Islander; $16 \%$ were Hispanic; $5 \%$ were black; and $4 \%$ were "other" or unknown race (Table 1). Within this cohort, 25\% of women had an index date between the years 2002-2007, and 75\% had an index date after 2007. Overall, 43\% were overweight or obese, and $10 \%$ had diabetes. Of the 15,459 women (81\%) with available BMD measurements, $46 \%$ had BMD in the osteoporotic range. Compared with women who had an index date before 2008, women with a later index date were more likely to be Hispanic (18\% vs. 10\%), to have diabetes (12\% vs. $5 \%$ ), to have experienced a clinical fracture before BP initiation (18\% vs. $12 \%$ ), to have a DXA scan $(85 \%$ vs. $70 \%)$, and were less likely to have a BMD indicative of osteoporosis (43\% vs. $56 \%$ ). Median follow-up was 21 months (IQR=9-36 months, mean $=24.6$ months)

\begin{tabular}{|c|c|c|c|}
\hline \multirow[b]{2}{*}{ Characteristics } & \multirow[b]{2}{*}{ All Women } & \multicolumn{2}{|c|}{$\begin{array}{c}\text { Index Year } \\
\text { (Year of Cohort Entry) }\end{array}$} \\
\hline & & $<2008$ & $\geq 2008$ \\
\hline Number of women, $\mathrm{n}$ & 19,091 & 4,830 & 14,261 \\
\hline Age, median (IQR) & $72(65-78)$ & $72(65-78)$ & $72(65-78)$ \\
\hline \multicolumn{4}{|l|}{ Race/ethnicity, n (\%) } \\
\hline White & $11,076(58.0)$ & $3,268(67.7)$ & $7,808(54.8)$ \\
\hline African American/black & $1,015 \quad(5.3)$ & $168(3.5)$ & $847 \quad(5.9)$ \\
\hline Hispanic/Latina & $3,008(15.8)$ & $491(10.2)$ & $2,517(17.6)$ \\
\hline Asian/Pacific Islander & $3,332(17.5)$ & $695(14.4)$ & $2,637(18.5)$ \\
\hline Other/mixed/unknown & $660 \quad(3.5)$ & $208 \quad(4.3)$ & $452 \quad(3.2)$ \\
\hline \multicolumn{4}{|c|}{ Index BMI category $\left(\mathrm{kg} / \mathrm{m}^{2}\right), \mathrm{n}(\%)$} \\
\hline $\begin{array}{l}\text { Normal/underweight } \\
(\mathrm{BMI}<25)\end{array}$ & $10,207(53.5)$ & $2,657(55.0)$ & $7,550(52.9)$ \\
\hline Overweight (BMI 25-<30) & $5,549(29.1)$ & $1,124(23.3)$ & $4,425(31.0)$ \\
\hline Obese $(\mathrm{BMI} \geq 30)$ & $2,700(14.1)$ & $436 \quad(9.0)$ & $2,264(15.9)$ \\
\hline Unknown & 635 (3.3) & $613(12.7)$ & $22(0.2)$ \\
\hline \multicolumn{4}{|c|}{ Charlson Comorbidity Index score, n (\%) } \\
\hline 0 & $11,404(59.7)$ & $3,245(67.2)$ & $8,159(57.2)$ \\
\hline $1-2$ & $5,658(29.6)$ & $1,284(26.6)$ & $4,374(30.7)$ \\
\hline$>2$ & $2,029(10.6)$ & $301 \quad(6.2)$ & $1,728(12.1)$ \\
\hline \multicolumn{4}{|c|}{ History of medical conditions, $\mathrm{n}(\%)$} \\
\hline Diabetes & $1,939(10.2)$ & $247(5.1)$ & $1,692(11.9)$ \\
\hline Rheumatoid arthritis & $552(2.9)$ & $195(4.04)$ & $357(2.5)$ \\
\hline $\begin{array}{l}\text { Grade } 3 \text { chronic kidney } \\
\text { disease }\end{array}$ & $3,152(16.5)$ & $804(16.6)$ & $2,348(16.5)$ \\
\hline \multicolumn{4}{|l|}{ Other medication use, $\mathrm{n}(\%)$} \\
\hline Proton pump inhibitors & $509(2.7)$ & $96 \quad(2.0)$ & $413(2.9)$ \\
\hline Aromatase inhibitors & $13(0.1)$ & $1 \quad(0)$ & $12(0.1)$ \\
\hline Glucocorticoids & $1,170 \quad(6.1)$ & $375 \quad(7.8)$ & $795 \quad(5.6)$ \\
\hline \multicolumn{4}{|l|}{ Fracture history, n (\%) } \\
\hline \multicolumn{4}{|l|}{ Before BP initiation } \\
\hline $\begin{array}{l}\text { Major osteoporotic } \\
\text { fractures }^{\mathrm{a}}\end{array}$ & $1,495 \quad(7.8)$ & $329(6.8)$ & $1,166 \quad(8.2)$ \\
\hline Any clinical fracture & $3177(16.6)$ & $580(12.0)$ & $2,597(18.2)$ \\
\hline \multicolumn{4}{|c|}{ Within 5 years before cohort entry } \\
\hline $\begin{array}{l}\text { Major osteoporotic } \\
\text { fractures }^{\mathrm{a}}\end{array}$ & $1,664 \quad(8.7)$ & $408 \quad(8.4)$ & $1,256 \quad(8.8)$ \\
\hline Any clinical fracture & $3,170(16.6)$ & $824(17.1)$ & $2,346(16.5)$ \\
\hline \multicolumn{4}{|l|}{ Bone mineral density } \\
\hline DXA tested, n (\%) & $15,459(81.0)$ & $3,356(69.5)$ & $12,103(84.9)$ \\
\hline T-score, median (IQR) & $\begin{array}{c}-2.4 \\
(-2.9 \text { to }-2.0)\end{array}$ & $\begin{array}{c}-2.6 \\
(-3.1 \text { to }-2.1)\end{array}$ & $\begin{array}{c}-2.4 \\
(-2.9 \text { to }-2.0) \\
\end{array}$ \\
\hline Osteoporosis, n (\%) & $7,047(45.6)$ & $1,869(55.7)$ & $5,178(42.8)$ \\
\hline Osteopenia, n (\%) & $8,006(51.8)$ & $1,351(40.3)$ & $6655(55.0)$ \\
\hline \multicolumn{4}{|c|}{$\begin{array}{l}\text { ancludes fractures of the hip, humerus, wrist, or spine. } \\
B M I=\text { body mass index; } B P=\text { bisphosphonate; } D X A=\text { dual-energy } x \text {-ray } \\
\text { absorptiometry scan; } I Q R=\text { interquartile range. }\end{array}$} \\
\hline
\end{tabular}

In Table 2, we present the estimated ORs and corresponding 95\% confidence intervals (CI) for the association of clinical risk factors with adherent BP continuation. Factors significantly associated with increased odds of BP continuation were 


\section{TABLE 2 Multivariable Adjusted ORs for Continuing Treatment Among Women Receiving BP}

\begin{tabular}{|c|c|c|c|}
\hline Predictor & OR $(95 \% \mathrm{CI})$ & Predictor & OR $(95 \% \mathrm{CI})$ \\
\hline \multicolumn{2}{|l|}{ Age, years } & \multicolumn{2}{|l|}{ Other medication use } \\
\hline $50-59$ & 1 & Proton pump inhibitors & $0.65(0.59-0.71)$ \\
\hline $60-69$ & $0.98(0.92-1.04)$ & Aromatase inhibitors & $0.92(0.69-1.24)$ \\
\hline $70-79$ & $1.06(1.00-1.13)$ & Glucocorticoids & $1.01(0.89-1.13)$ \\
\hline$\geq 80$ & $1.00(0.93-1.07)$ & \multicolumn{2}{|l|}{ History of fractures before BP initiation } \\
\hline \multicolumn{2}{|l|}{ Race/ethnicity } & Hip & $0.90(0.80-1.01)$ \\
\hline White & 1 & Spine & $0.98(0.84-1.15)$ \\
\hline African American/black & $0.93(0.86-1.01)$ & Humerus & $0.95(0.82-1.10)$ \\
\hline Hispanic/Latina & $0.89(0.85-0.94)$ & Wrist & $1.06(0.94-1.18)$ \\
\hline Asian/Pacific Islander & $0.90(0.85-0.94)$ & Other skeletal site & $0.95(0.90-1.01)$ \\
\hline Current smoking & $1.04(0.96-1.14)$ & \multicolumn{2}{|l|}{ History of fractures in previous 12 months } \\
\hline Low education census block & $1.04(0.99-1.10)$ & Hip & $0.61(0.52-0.71)$ \\
\hline Low income census block & $1.05(0.97-1.13)$ & Spine & $0.87(0.76-1.00)$ \\
\hline Index year (year of cohort entry) $<2008$ & $1.35(1.29-1.41)$ & Humerus & $0.79(0.66-0.94)$ \\
\hline \multicolumn{2}{|l|}{ BMI category $\left(\mathrm{kg} / \mathrm{m}^{2}\right)$} & Wrist & $1.11(0.96-1.28)$ \\
\hline $\begin{array}{l}\text { Normal/underweight }(\mathrm{BMI}<25) \\
\text { Overweight }(\text { BMI } 25-<30)\end{array}$ & $\frac{1}{0.99(0.95-1.03)}$ & Other skeletal site & $0.90(0.84-0.97)$ \\
\hline Obese $(\mathrm{BMI} \geq 30)$ & $1.00(0.94-1.05)$ & \multicolumn{2}{|l|}{ BMD T-score } \\
\hline \multicolumn{2}{|l|}{ Charlson Comorbidity Index score } & $>-2.0$ & 1 \\
\hline 0 & 1 & -2.0 to $>-2.5$ & $1.31(1.25-1.38)$ \\
\hline 1 & $0.99(0.94-1.05)$ & -2.5 to $>-3.0$ & $1.48(1.39-1.57)$ \\
\hline 2 & $0.97(0.91-1.03)$ & $\leq-3.0$ & $1.57(1.47-1.68)$ \\
\hline$>2$ & $0.91(0.84-0.98)$ & \multicolumn{2}{|l|}{ Time on follow-up } \\
\hline \multicolumn{2}{|l|}{ History of medical conditions } & $<6$ months & 1 \\
\hline Diabetes & $1.08(1.01-1.16)$ & 6 months to 1 year & $1.16(1.09-1.24)$ \\
\hline Rheumatoid arthritis & $0.89(0.80-0.99)$ & Year 2 & $1.24(1.18-1.31)$ \\
\hline \multicolumn{2}{|l|}{ Chronic kidney disease } & Year 3 & $1.29(1.21-1.36)$ \\
\hline Grade $3 \mathrm{a}$ & $1.00(0.95-1.06)$ & Year 4 & $1.27(1.19-1.36)$ \\
\hline Grade $3 b$ & $0.91(0.82-1.00)$ & Year 5 & $1.26(1.17-1.36)$ \\
\hline
\end{tabular}

(a) index date before $2008(\mathrm{OR}=1.35$, 95\% CI=1.29-1.41); (b) most recent BMD T-score -2 to $-2.4(\mathrm{OR}=1.31,95 \% \mathrm{CI}=1.25$ 1.38), T-score -2.5 to $-2.9(\mathrm{OR}=1.48,95 \% \mathrm{CI}=1.39-1.57)$, and T-score $\leq-3.0(\mathrm{OR}=1.57,95 \% \mathrm{CI}=1.47-1.68)$ versus $\mathrm{T}$-score above -2.0; (c) history of diabetes mellitus ( $\mathrm{OR}=1.08$, 95\% $\mathrm{CI}=1.01-1.16$ ); and (d) longer duration of follow-up (referent group < 6 months; $\mathrm{OR}=1.16,95 \% \mathrm{CI}=1.09-1.24$ for 6 months1 year; $\mathrm{OR}=1.24,95 \% \mathrm{CI}=1.18-1.31$ for $1-2$ years; $\mathrm{OR}=1.29$, $95 \% \mathrm{CI}=1.21-1.36$ for $2-3$ years; $\mathrm{OR}=1.27,95 \% \mathrm{CI}=1.19-1.36$ for 3-4 years; and $\mathrm{OR}=1.26,95 \% \mathrm{CI}=1.17-1.36$ for $4-5$ years).

On the other hand, factors significantly associated with decreased odds of continued BP were (a) a recent hip $(\mathrm{OR}=0.61$, 95\% CI =0.52-0.71), humerus ( $\mathrm{OR}=0.79,95 \% \mathrm{CI}=0.66-0.94)$, or other (nonmajor osteoporotic) fracture $(\mathrm{OR}=0.90,95 \%$ $\mathrm{CI}=0.84-0.97)$; (b) proton pump inhibitor use $(\mathrm{OR}=0.65,95 \%$ $\mathrm{CI}=0.59-0.71)$; (c) history of rheumatoid arthritis $(\mathrm{OR}=0.89$, 95\% CI = 0.80-0.99); (d) Charlson Comorbidity Index score $>2$ $(\mathrm{OR}=0.91,95 \% \mathrm{CI}=0.84-0.98)$; and (e) Hispanic $(\mathrm{OR}=0.89$, $95 \% \mathrm{CI}=0.85-0.94)$ and $A \operatorname{sian}(\mathrm{OR}=0.90,95 \% \mathrm{CI}=0.85-0.94)$ race/ethnicity versus white.
Age, smoking status, estimated low income, estimated low educational attainment, black race, grade 3 CKD, overweight/ obesity, glucocorticoid use, aromatase inhibitor use, recent spine or wrist fracture, and history of major osteoporotic fracture (hip, spine, wrist, or humerus) before BP initiation were not associated with BP continuation.

\section{Discussion}

Among women who received long-term osteoporosis therapy within Kaiser Permanente Southern California, we found that having an index date before 2008 and lower BMD T-scores were significantly associated with greater likelihood of continuing BP treatment. Conversely, other clinical factors, such as recent fracture, and use of proton pump inhibitors were significantly associated with reduced likelihood of continuing oral BP treatment. We also observed an association of diabetes mellitus, rheumatoid arthritis, comorbidity burden, and Hispanic and Asian race/ethnicity with BP treatment behavior.

These data expand our current knowledge by providing an initial assessment of clinical factors associated with 
sustained BP continuation in a large clinical cohort of postmenopausal women who were previously treated for at least 5 years. That lower recent T-scores are associated with greater continuation beyond 5 years seems intuitive. Women with lower BMD (and their providers) may be more concerned about skeletal health and the need for continued adherent treatment. The association of recent fracture with lower likelihood of continued treatment may be attributable to interruption or change in therapy. Further efforts should be directed to examining osteoporosis treatment behaviors and subsequent fracture risk after patients experience an osteoporotic fracture while on BP therapy. The much lower odds of oral BP continuation associated with pharmacologic proton pump inhibitor use is expected, given potential gastrointestinal effects of oral BP; additional use of over-the-counter proton pump inhibitors was not available in our pharmacy databases.

The association of earlier cohort entry (index date before 2008) with treatment continuation may reflect later era riskbenefit considerations of whether very long-term treatment was indicated or appropriate and concerns regarding potential side effects. The current study confirms our previous finding reported from a northern California cohort of women receiving long-term BP therapy, where a decline in continuation of longterm therapy (up to 3 and 5 years) was also evident in later compared with earlier treatment eras. ${ }^{21}$

\section{Strengths and Limitations}

A major strength of this study is the large number of women who initiated and continued adherent BP therapy within an integrated health care delivery system. The source population included all women enrolled as members within Kaiser Permanente Southern California, which has been shown to comprise a representative sample of the region. ${ }^{22}$ The goal of our analyses was to assess determinants of BP continuation among women on BP beyond 5 years, a population that is growing in size but has been relatively understudied. These data may inform efforts to further understand patient and provider behaviors relative to treatment continuation among those receiving long-term BP therapy.

This study also has some limitations to consider. First, BMD was not systematically measured for all women; however, about 4 out of 5 study participants had 1 or more BMD measurements before BP treatment initiation or during treatment. Second, treatment was determined from pharmacy dispensing records, which may or may not accurately represent BP exposure. However, our centralized pharmacy databases provide complete capture of health plan dispensed prescriptions, and members are financially incentivized to use health plan pharmacies. Third, a specified adherence threshold was used, below which women were considered to have discontinued adherent treatment even if they were receiving some drug. This misclassification may have caused an underestimate in the numbers of women continuing BP.
Finally, this study used a minimum adherence level of $60 \%$ to reflect osteoporosis treatment behaviors in the clinical setting. Other studies have used a lower adherence threshold of $50 \%$ or a higher threshold of $80 \%,{ }^{23,24}$ both of which have been associated with differential fracture outcome. We did not consider interactions between covariates; only main associations of each covariate with the outcome were assessed.

\section{Conclusions}

$\overline{\text { This study evaluated predictors of BP continuation beyond }}$ 5 years of treatment using contemporary medical record data Our findings suggest that among long-term BP users, several expected factors appear to influence treatment continuation, specifically low BMD, recent fracture, and era of treatment initiation. Our data indicate an interesting secular trend in BP continuation, also reported elsewhere ${ }^{21}$ - since 2008, BP use beyond the initial 5 years of treatment was less common than in the previous years.

\section{Authors}

MONIKA A. IZANO, PhD, MS, MA; JOAN C. LO, MD; BRUCE ETTINGER MD; and ROMAIN NEUGEBAUER, PhD, Division of Research, Kaiser Permanente Northern California, Oakland. SUSAN M. OTT, MD, Department of Medicine, University of Washington, Seattle. BONNIE H. LI, MS, and ANNETTE L. ADAMS, PhD, MPH, Department of Research \& Evaluation, Kaiser Permanente Southern California, Pasadena. FANG NIU, MS, and RITA L. HUI, PharmD, MS, Pharmacy Outcomes Research Group, Kaiser Permanente California, Downey and Oakland.

AUTHOR CORRESPONDENCE: Annette L. Adams, PhD, MPH, Department of Research \& Evaluation, Kaiser Permanente Southern California, 100 S. Los Robles Ave., 2nd Fl., Pasadena, CA 91101. Tel.: 626.564.3916; E-mail: Annette.L.Adams@kp.org.

\section{DISCLOSURES}

This study was supported by a grant from the National Institute on Aging and National Institute of Arthritis, Musculoskeletal and Skin Diseases at the National Institutes of Health (NIH; R01AG047230, S1). The content is solely the responsibility of the authors and does not necessarily represent the official views of the NIH or Kaiser Permanente. Lo has received previous research funding from Amgen and Sanofi, unrelated to the current study. Adams has received previous research funding from Merck, Amgen, Otsuka, and Radius Health, unrelated to the current study. Ettinger has served as an expert witness for Teva Pharmaceuticals, unrelated to the current study. Ott previously attended a scientific advisory meeting for Amgen but declined the honorarium. The other authors have nothing to disclose.

These data were presented at the 2018 Annual Meeting of the American Society of Bone and Mineral Research (ASBMR), September 28-October 1, 2018, Montreal, Quebec, Canada. 


\section{REFERENCES}

1. Bilezikian JP. Efficacy of bisphosphonates in reducing fracture risk in postmenopausal osteoporosis. Am J Med. 2009;122(2 Suppl):S14-S21.

2. Black DM, Cummings SR, Karpf DB, et al. Randomised trial of effect of alendronate on risk of fracture in women with existing vertebral fractures Fracture Intervention Trial Research Group. Lancet. 1996;348(9041):1535-41.

3. Schwartz AV, Bauer DC, Cummings SR, et al. Efficacy of continued alendronate for fractures in women with and without prevalent vertebral fracture: the FLEX trial. J Bone Miner Res. 2010;25(5):976-82.

4. Whitaker M, Guo J, Kehoe T, Benson G. Bisphosphonates for osteoporosis-where do we go from here? N Engl J Med. 2012;366(22):2048-51.

5. Hui RL, Adams AL, Niu F, et al. Predicting adherence and persistence with oral bisphosphonate therapy in an integrated health care delivery system. J Manag Care Spec Pharm. 2017;23(4):503-12. Available at: https://www. jmcp.org/doi/10.18553/jmcp.2017.23.4.503.

6. Izano MA, Neugebauer R, Ettinger B, et al. Using pharmacy data and adherence to define long-term bisphosphonate exposure in women. J Manag Care Spec Pharm. 2019;25(6):719-23. Available at: https://www.jmcp.org/ doi/10.18553/jmcp.2019.25.6.719.

7. Baillie C. Continuing alendronate for an additional 5 years maintained bone mineral density in postmenopausal women. Evid Based Med. 2007;12(3):70.

8. Delmas PD. Use of alendronate after 5 years of treatment. JAMA. 2007;297(18):1979-80; author reply 1980-81.

9. Erviti J, Gorricho J. Use of alendronate after 5 years of treatment. JAMA. 2007;297(18):1979; author reply 1980-81

10. Kraenzlin ME, Meier C. Does continued alendronate therapy improve bone mineral density and reduce fracture risk in postmenopausal women? Nat Clin Pract Endocrinol Metab. 2007;3(10):686-87.

11. Lane NE. Long-term effects of treatment with alendronate for patients with osteoporosis. Nat Clin Pract Rheumatol. 2007;3(8):426-27.

12. Black DM, Schwartz AV, Ensrud KE, et al. Effects of continuing or stopping alendronate after 5 years of treatment: the Fracture Intervention Trial Long-term Extension (FLEX): a randomized trial. JAMA. 2006;296(24): 2927-38.

13. Dawson-Hughes B. A revised clinician's guide to the prevention and treatment of osteoporosis. J Clin Endocrinol Metab. 2008;93(7):2463-65.
14. Advisory Task Force on Bisphosphonate-Related Ostenonecrosis of the Jaws, American Association of Oral and Maxillofacial Surgeons. American Association of Oral and Maxillofacial Surgeons position paper on bisphosphonate-related osteonecrosis of the jaws. J Oral Maxillofac Surg. 2007;65(3):369-76.

15. Khosla S, Burr D, Cauley J, et al. Bisphosphonate-associated osteonecrosis of the jaw: report of a task force of the American Society for Bone and Mineral Research. J Bone Miner Res. 2007;22(10):1479-91.

16. Shane E, Burr D, Ebeling PR, et al. Atypical subtrochanteric and diaphyseal femoral fractures: report of a task force of the American Society for Bone and Mineral Research. J Bone Miner Res. 2010;25(11):2267-94.

17. Deyo RA, Cherkin DC, Ciol MA. Adapting a clinical comorbidity index for use with ICD-9-CM administrative databases. J Clin Epidemiol. 1992;45(6):613-19.

18. Levey AS, Stevens LA, Schmid CH, et al. A new equation to estimate glomerular filtration rate. Ann Intern Med. 2009;150(9):604-12.

19. Lo JC, Hui RL, Grimsrud CD, et al. The association of race/ethnicity and risk of atypical femur fracture among older women receiving oral bisphosphonate therapy. Bone. 2016;85:142-47.

20. Leong TK, Tabada GH, Yang J, Zhu Z, Neugebauer R. MSMstructure. 2016. SAS Macro. Retrieved February 23, 2018. Available at: https://divisionofresearch.kaiserpermanente.org/projects/biostatistics/causalinferencesoftware. Accessed January 17, 2020

21. Juergens N, Ettinger B, Hui R, Chandra M, Lo JC. Secular trends in longterm oral bisphosphonate use. J Gen Intern Med. 2019;34(8):1383-84.

22. Koebnick C, Langer-Gould AM, Gould MK, et al. Sociodemographic characteristics of members of a large, integrated health care system: comparison with U.S. Census Bureau data. Perm J. 2012;16(3):37-41.

23. Adams AL, Adams JL, Raebel MA, et al. Bisphosphonate drug holiday and fracture risk: a population-based cohort study. J Bone Miner Res. 2018; 33(7):1252-59

24. Siris ES, Harris ST, Rosen CJ, et al. Adherence to bisphosphonate therapy and fracture rates in osteoporotic women: relationship to vertebral and nonvertebral fractures from 2 U.S. claims databases. Mayo Clin Proc. 2006;81(8):1013-22. 